\title{
A Game Model of Optimal Apartment Cleaning by College Students
}

\author{
Amitrajeet A. Batabyal \\ Department of Economics, Rochester Institute of Technology, Rochester, NY, USA \\ Email: aabgsh@rit.edu
}

How to cite this paper: Batabyal, A.A. (2017) A Game Model of Optimal Apartment Cleaning by College Students. Theoretical Economics Letters, 7, 218-222. https://doi.org/10.4236/tel.2017.72019

Received: January 24, 2017

Accepted: February 25, 2017

Published: February 28, 2017

Copyright (C) 2017 by author and Scientific Research Publishing Inc. This work is licensed under the Creative Commons Attribution International License (CC BY 4.0).

http://creativecommons.org/licenses/by/4.0/

\begin{abstract}
In this note we use a static game model to analyze the optimal cleanup of an apartment that is shared by two college students. Both students dislike cleaning. However, they also prefer a clean apartment to a dirty one. Student is utility function embodies the idea that the more time one student spends cleaning, the less valuable is the time spent cleaning by the other student. In this setting, we first determine the best response function of each student (player) $i$ where $i=1,2$. Second, we determine the cleaning time choices that survive one round of the iterated elimination of strictly dominated strategies (IESDS). Finally, we ascertain the cleaning time choices that survive all rounds of IESDS.
\end{abstract}

\section{Keywords}

Apartment, Cleanup, College Student, Static Game, Strictly Dominated Strategy

\section{Introduction}

Readers who have been college students in the United States will know that such students frequently spend their first (freshman) and sometimes their second (sophomore) year living in dormitories. However, after the completion of their sophomore year, these students often shift to either an on-campus or to an offcampus apartment. In some institutions of higher learning, quite apart from a desire for greater independence on the part of the students, such a move is mandated by the fact that the relevant institution is able to guarantee housing only to a fraction of all enrolled students. ${ }^{1}$

Dormitory living in most institutions generally does not involve any note-

${ }^{1}$ See Tietjen [1] for additional details on this point and for a listing of the dormitory capacities of a number of different institutions of higher learning in the United States. 
worthy cleaning activities on the part of the students because custodial staff are standardly present to take care of most cleaning activities. However, this state of affairs clearly changes once students move into their own apartments. In this new living arrangement, the cleanliness of a shared apartment depends ultimately on the time spent by the individual students in keeping this apartment clean.

The available evidence shows without any ambiguity that students sharing apartments frequently get into conflicts because of a variety of reasons, not the least of which is their heterogeneous preferences for cleanliness. ${ }^{2}$ Thus, it is no surprise that tales about the putative disadvantages of living either with "neatfreaks" or with "slobs" are legion in American popular culture. Departments of residential life and housing in institutions of higher learning routinely counsel students about the ways in which they can avert conflicts arising from misunderstood or poorly defined apartment cleaning chores. Therefore, the problem of the apposite division of responsibilities for cleaning a shared apartment is both commonplace and relevant.

To the best of our knowledge, Batabyal [6] is the only paper to have formally studied aspects of the apartment cleanup problem that we have just referred to. Specifically, Batabyal [6] analyzes a static game model of apartment cleaning and determines the Nash equilibrium cleanup times in the optimal apartment cleaning game. The analysis in the present note also involves the study of a static game model of optimal apartment cleaning but our focus is on strictly dominated strategies and on the iterated elimination of strictly dominated strategies (IESDS).

Specifically, we use a static game of complete information ${ }^{3}$ model to analyze the optimal cleanup of an apartment that is shared by two college students. Both students dislike cleaning. However, they also prefer a clean apartment to a dirty one. Student $i^{\prime} s$ utility function captures the idea that the more time one student spends cleaning, the less valuable is the time spent cleaning by the other student. Section 2.1 describes the static game model we utilize to conduct the analysis. Section 2.2 determines the best response function of each student (player) $i$ where $i=1,2$ Section 2.3 ascertains the cleaning time choices that survive one round of IESDS. In section 2.4, we investigate the cleaning time choices that survive all rounds of IESDS. Section 3 concludes and then offers two suggestions for extending the research described in this note.

\section{Analysis}

\subsection{The Game Model}

Consider a scenario in which two college students share an apartment. Student $i$, where $i=1,2$, selects a non-negative amount of time $\tau \geq 0$ to clean the apart-

${ }^{2}$ See Ogletree et al. ([2], [3]) and Yadegaran ([4], [5]) for a more elaborate corroboration of this claim.

${ }^{3}$ See Gibbons ([7], pp. 1-54) or Tadelis ([8], pp. 43-128) for textbook expositions of static games of complete information. 
ment under study. If we denote the cleaning time choices of the two students by $\tau_{i} \geq 0$ and $\tau_{j} \geq 0$ then student $i$ s concave utility function is given by

$$
U_{i}\left(\tau_{i}, \tau_{j}\right)=\left(10-\tau_{j}\right) \tau_{i}-\tau_{i}^{2} .
$$

Two points are now worth stressing. First, our choice of the positive real number 10 in Equation (1) simplifies the ensuing mathematical analysis we undertake. It is, for all practical purposes, without loss of generality. In this regard, we emphasize that an analysis of the sort we undertake in this note can be conducted for any positive real number.

Second, consistent with the discussion in section 1, the particular form of the utility function in Equation (1) is designed to succinctly capture the following idea that we believe is salient in the context of apartment cleaning by college students: the more time one student spends cleaning, the less valuable is the time spent cleaning by the other student. Therefore, if we were to replace Equation (1) with $U_{i}\left(\tau_{i}, \tau_{j}\right)=\left(10+\tau_{j}-\tau_{i}\right) \tau_{i}$ then this latter function would not capture the above idea. In this regard, the reader should not interpret the utility function in Equation (1) as saying that the ith student obtains disutility from the time spent cleaning by the $j$ th student. ${ }^{4}$ Given this background, our next task is to determine the best response function of student (player) $i$ where $i=1,2$.

\subsection{The Best Response Function}

We begin by maximizing student is utility function in Equation (1), given his belief about the time spent cleaning by the other player or $\tau_{j}$. Specifically, the ith student solves

$$
\max _{\left\{\tau_{i} \geq 0\right\}}\left\{\left(10-\tau_{j}\right) \tau_{i}-\tau_{i}^{2}\right\}
$$

The first order necessary condition for a maximum is ${ }^{5}$

$$
10-\tau_{j}-2 \tau_{i}=0
$$

which implies that student is best response function is

$$
\tau_{i}=\frac{10-\tau_{j}}{2}
$$

Which cleaning time choices by the two students survive one round of IESDS? We now proceed to answer this question.

\subsection{Choices Surviving One Round of IESDS}

Suppose student $i$ chooses $\tau_{i}=5$. Given that student $j$ selects $\tau_{j}$, the utility to the ith student from the choice of $\tau_{i}=5$ is

$$
U_{i}\left(5, \tau_{j}\right)=5\left(10-\tau_{j}\right)-25=25-5 \tau_{j}
$$

Now suppose that student $i$ chooses $5+\epsilon$ where $\epsilon>0$. If student $j$ selects $\tau_{j}$ then the utility to student $i$ from this choice is

\footnotetext{
${ }^{4}$ One way to extend the analysis in this note would be to work with the utility function

$U_{i}\left(\tau_{i}, \tau_{j}\right)=\left(A_{i}+\tau_{j}-\tau_{i}\right) \tau_{i}$ where $A_{i}$ is a student specific parameter.
}

${ }^{5}$ The reader can check to see that the second order sufficiency condition is satisfied. 


$$
U_{i}\left(5+\epsilon, \tau_{j}\right)=(5+\epsilon)\left(10-\tau_{j}\right)-(5+\epsilon)^{2}=25-5 \tau_{j}-\epsilon^{2}-\epsilon \tau_{j}
$$

Since $\epsilon>0$, inspecting the right-hand-sides (RHSs) of equations (5) and (6), it follows that

$$
U_{i}\left(5, \tau_{j}\right)>U_{i}\left(5+\epsilon, \tau_{j}\right)
$$

The discussion in the preceding paragraph tells us that given the belief that student $j$ selects $\tau_{j}$, the choice of $\tau_{i}=5$ is a best response to $\tau_{j}=0$. In turn, this tells us that any cleaning time choice $\tau_{i}>5$ is strictly dominated by $\tau_{i}=5$. Summing up, we see that the cleaning time choices $\tau_{i} \in[0,5]$ are the ones that survive one round of IESDS. We now proceed to our final task and that is to determine the cleaning time choices that survive all rounds of IESDS.

\subsection{Choices Surviving All Rounds of IESDS}

We begin by pointing out that the IESDS solution concept is attractive because it does not require the existence of a strictly dominant strategy and nor does it require the existence of strictly dominated strategies. Now, to accomplish the task before us, we follow the methodology discussed in Tadelis ([8], pp. 65-67). Note that in the second round of the process of elimination, because $\tau_{2} \leq 5$, the best response function $\tau_{i}=\left(10-\tau_{j}\right) / 2$ - see Equation (4)-implies that student 1 will choose $\tau_{1} \geq 2.5$ and a similar symmetric argument applies to student 2 . This tells us that the strategy sets that survive the second round of the elimination of strictly dominated strategies are $\tau_{i} \in[2.5,5]$ for $i=1,2$.

If this elimination process were to converge to an interval and not to a single point in the respective strategy sets then by symmetry between the two students, the interval of interest would be some $\left[\tau_{\min }, \tau_{\max }\right]$ that simultaneously satisfies two equations in two unknowns that are given by

$$
\tau_{\min }=\frac{10-\tau_{\max }}{2} \text { and } \tau_{\max }=\frac{10-\tau_{\min }}{2} .
$$

Having said this, it is straightforward to verify that the only solution to the two equations in (8) is $\tau_{\min }=\tau_{\max }=10 / 3$. Therefore, we deduce that the unique pair of cleaning time choices by the two students that survive all rounds of IESDS is given by

$$
\tau_{1}=\tau_{2}=\frac{10}{3}
$$

When the cleaning times chosen by the two students are in accordance with Equation (9), straightforward substitution in Equation (1) shows that the $i$ th student's maximized utility is $U_{i}(10 / 3,10 / 3)=100 / 9$. This completes our gametheoretic analysis of the optimal cleaning of an apartment shared by two college students.

\section{Conclusions}

In this note we used a static game model to analyze the optimal cleanup of an apartment that was shared by two college students. Both students disliked 
cleaning. However, they also preferred a clean apartment to a dirty one. Student is utility function embodied the idea that the more time one student spent cleaning, the less valuable was the time spent cleaning by the other student. In this setting, we first determined the best response function of each student or player $i$ where $i=1,2$. Second, we determined the cleaning time choices that survived one round of IESDS. Finally, we ascertained the cleaning time choices that survived all rounds of IESDS.

The analysis in this note can be extended in a number of different directions. Along with footnote 4 , here are three suggestions for extending the research described here. First, it would be useful to introduce different degrees of aversion to cleaning on the part of the students in the model and then analyze scenarios in which it is possible for one student to make side payments to the other to avoid cleaning duties. Second, in a dynamic and stochastic setting, it would be helpful to see if the two students are able to come up with a cleaning schedule that is renegotiation-proof. Finally, it would also be interesting to analyze the apartment cleaning problem when the two agents under consideration are either domestic partners or spouses. Studies of apartment cleaning and, more generally, the performance of necessary chores by busy college students and other agents that incorporate these aspects of the problem into the analysis will provide additional insights into a time allocation problem that has important economic and social ramifications for young people.

\section{Acknowledgements}

Batabyal thanks three anonymous reviewers for their helpful comments on a previous version of this paper and Cassandra Shellman for her help in formatting the final version of the paper. In addition, he acknowledges financial support from the Gosnell endowment at RIT. The usual disclaimer applies.

\section{References}

[1] Tietjen, D. (2015) Colleges with the Lowest Dorm Capacities. Forbes, July 31.

[2] Ogletree, S.M., Turner, G.M., Viera, A. and Brunotte, J. (2005) College Living: Issues Related to Housecleaning Attitudes. College Student Journal, 39, 729-733.

[3] Ogletree, S.M., Worthen, J.B., Turner, G.M. and Vickers, V. (2006) Developing an Attitudes toward Housecleaning Scale: Gender Comparisons and Counseling Applications. The Family Journal, 14, 400-407. https://doi.org/10.1177/1066480706289589

[4] Yadegaran, J. (2013) College Roommates: Five Tips for Keeping the Peace. San Jose Mercury News, August 7.

[5] Yadegaran, J. (2013) Seven College Roommate Conflicts-and Solutions. San Jose Mercury News, August 7.

[6] Batabyal, A.A. (2016) Optimal Apartment Cleaning by Harried College Students: A Game-Theoretic Analysis. Unpublished Manuscript, Rochester Institute of Technology.

[7] Gibbons, R. (1992) A Primer in Game Theory. Pearson Education Limited, Harlow, Essex, United Kingdom.

[8] Tadelis, S. (2013) Game Theory. Princeton University Press, Princeton, New Jersey. 
Submit or recommend next manuscript to SCIRP and we will provide best service for you:

Accepting pre-submission inquiries through Email, Facebook, LinkedIn, Twitter, etc. A wide selection of journals (inclusive of 9 subjects, more than 200 journals)

Providing 24-hour high-quality service

User-friendly online submission system

Fair and swift peer-review system

Efficient typesetting and proofreading procedure

Display of the result of downloads and visits, as well as the number of cited articles Maximum dissemination of your research work

Submit your manuscript at: http://papersubmission.scirp.org/

Or contact tel@scirp.org 